\title{
To Be or Not To Be in Office Again, That is the Question Political Business Cycles with Local Governments
}

\author{
Rui Nuno Baleiras \\ U niversidade $\mathrm{N}$ ova de L isboa \\ Fauldade de $\mathrm{E}$ conomia \\ Travessa de E stêvão Pinto (C ampolide) \\ P-1099-032 LISBOA, PORTUG A L
}

\author{
José da Silva Costa \\ U niversidade do Porto \\ Faculdade de E onomia \\ Rua D r. Roberto Frias \\ P-4200-464 PORT 0, PORTUGA L
}

March 2001

\begin{abstract}
Most opportunistic-type models of political business cycles tend to posit a given objective for incumbents: maximisation of re-election chances. Though taking an opportunistic view too, we suggest a new explanation for a fiscal policy cycle: the incumbent's concern with her own welfare in cases of victory and defeat. This rationale addresses local policy-making in particular. An equilibrium perfectforesight model is designed which totally dispenses with any form of irrationality (namely, on the part of voters) or the common objective functions (re-election chances). Being well grounded in basic microeconomic theory (welfare maximisation by the individual agent), our model provides another foundation for the emergence of political business cycles at the local level.

The empirical plausibility of theoretical predictions is then tested on Portuguese municipal data ranging from 1977 to 1993. The estimation of an error-components econometric framework finds evidence in favour of the proposed explanation and enlightens the role played by several politicoeconomic determinants of local governments' investment outlays, such as electoral calendar, re-candidacy decisions, political cohesion and intergovernmental capital transfers.
\end{abstract}

Keywords: local public finance; public choice; political business cycles; elections; Portugal. JEL's classification: C23; D72; H41; H72; R51.

${ }^{\S}$ Corresponding author: voice $=+351-2138016$ 00; fax =+351-21 3886073 ; e-mail = rnbaleiras@ fe.unl.pt. 


\title{
To Be or Not To Be in Office Again, That is the Question Political Business Cycles with Local Governments
}

March 2001

\begin{abstract}
Most opportunistic-type models of political business cycles tend to posit a given objective for incumbents: maximisation of re-election chances. Though taking an opportunistic view too, we suggest a new explanation for a fiscal policy cycle: the incumbent's concern with her own welfare in cases of victory and defeat. This rationale addresses local policy-making in particular. An equilibrium perfectforesight model is designed which totally dispenses with any form of irrationality (namely, on the part of voters) or the common objective functions (re-election chances). Being well grounded in basic microeconomic theory (welfare maximisation by the individual agent), our model provides another foundation for the emergence of political business cycles at the local level.

The empirical plausibility of theoretical predictions is then tested on Portuguese municipal data ranging from 1977 to 1993. The estimation of an error-components econometric framework finds evidence in favour of the proposed explanation and enlightens the role played by several politicoeconomic determinants of local governments' investment outlays, such as electoral calendar, re-candidacy decisions, political cohesion and intergovernmental capital transfers.
\end{abstract}

Keywords: local public finance; public choice; political business cycles; elections; Portugal. JEL's classification: C23; D72; H41; H72; R51.

\section{Introduction}

In very broad terms, political business cycle (PBC) analysis concerns short-run government behaviour within election dates. It is believed that authorities run economic policy in typical intertemporal patterns each office term. ${ }^{1}$ Theoretical approaches have searched for justifications of such patterns while empirical inquiries have tested their reliability with actual data.

The analysis in this paper pivots around the foundations of opportunistic PBC modelling. It combines a new explanation with an empirical test at the local government level. In the political economy literature at large, it is commonly argued that incumbents seek re-election and challengers strive to reach office. For instance, Kraan (1996, p. 62) has written: "According to the dominant view in the public choice literature, the objective function of politicians is the maximisation of electoral votes (...)." A similar remark is made by McNutt (1996, p. 9). This

\footnotetext{
* The authors thank Vasco Santos and Friedrich Schneider for insightful remarks, as well as the helpful reactions by Pedro P. Barros, Carlo Devillanova, Frédéric Gannon, Andreas Irmen, Rogério P. Leal, Jacques-François Thisse, and Robert Waldmann. Comments from seminar participants at the Swiss Federal Institute of Technology (Zurich), Universidade Nova de Lisboa (Lisbon), and the University of Warwick (Coventry) are also gratefully acknowledged. Remaining shortcomings are our own.

1 A different, historically oriented strand of literature has focused on the long-run interaction cycles between economic performance and political systems, seeking ties with the well-known economic history concepts of Kuznets and Kondratieff fluctuations. A flavour of this avenue can be found in Soldatos (1994).
} 
belief has indeed spread to the PBC literature. Earlier seminal opportunistic models were recently reprinted in Frey (1997) under the suggestive heading of "vote maximising models".2 Modern examples of PBC models where incumbents aim at maximising their re-election chances are Nordhaus (1989), Shachar (1993) and Reed (1994). Our paper disputes this view because we believe it lacks realism and follows from a spurious modelling option.

The motivation to dispute the dominant opportunistic view springs from the fact that political activity is fraught with risk. Electorally appointed jobs are scarce when compared to the number of potential candidates. Under democratic rules, administration positions are subject to turnover rates much higher than elsewhere in the economy. Incumbents who fail to be re-elected in general have no certain employment prospects in other public sector offices. These women and men must find an alternative job in case they fail re-election. It therefore seems quite reasonable to expect rational incumbents to bear in mind outside income (that is, income earned outside the public sector) when making their fiscal policy decisions. This behaviour looks even more plausible at the local rather than the central government tier since the uncertainty on future political appointments is greater for local than for higher-rank politicians. ${ }^{3}$ The maximisation of re-election chances alone sounds a rather spurious modelling option because the incumbent's expected utility upon uncertain events is impaired once one of the feasible alternatives, electoral defeat, is ignored beforehand.

Our paper hopes, therefore, to work out the implications of a simultaneous consideration of the two feasible electoral outcomes: to be or not to be in office in the following term. Though proceeding from an opportunistic view too, we are able to suggest a different explanation for a fiscal policy cycle: the incumbent's concern with her own welfare in case of no re-election. The analysis extends the framework of Baleiras (1997). An equilibrium perfect-foresight model is designed which totally dispenses with any form of irrationality (namely, on the part of voters) or the common objective functions (re-election chances). Being well grounded in basic microeconomic theory (own-welfare maximisation by the individual agent), our analysis provides another foundation for the emergence of PBCs.

\footnotetext{
${ }^{2}$ See Drazen (2000) for a fresh survey of the PBC literature.

3 The difficulty local incumbents face in finding a future political appointment in case of no re-election has been documented for the case of Portugal. Mozzicafreddo et al. (1991, p. 45) found that "(...) very curiously, the political career of mayors (Presidentes de Câmara) initiates and ends at the local level, barely holding positions in the cabinet, the central administration or in the national bodies of political parties. The only link, with some significance, between central and local tiers is the seating at the national parliament before municipal activity-this has been the case of 27.3 per cent of surveyed mayors." These conclusions follow from a survey analysis involving 55 mayors in 1986 and a case-study approach focusing on five municipalities from 1976 to 1987. Moreover, centralgovernment politicians enjoy a lifetime compensation upon exit of (at least an eight-year long) political activity on top of any retirement allowance they may be entitled to (the minimum eligible period has changed to twelve years from 1996 onwards); local-government politicians are not entitled to such compensation.
} 
The outlined model is then applied to a panel data sample of Portuguese local governments. This application serves a twofold purpose. First, it provides a test on the empirical plausibility of theoretical predictions. The methodology is quite general and can easily be adapted to other national contexts. Second, it creates the opportunity to try to improve the understanding of the Portuguese local finance system. Panel data offer several advantages vis-àvis time-series and cross-section observations alone and have attracted an increasing number of economic applications in recent years. In particular, many empirically oriented PBC papers have resorted to these samples. Examples at the central government tier are Roubini and Sachs (1989a,b), Alesina and Roubini (1992), Alesina et al. (1993) and Schuknecht (1999, 2000) while at sub-national tiers we can cite Blais and Nadeau (1992). In all these cases, individual idiosyncrasies are modelled as deterministic effects from the outset and are not open to discussion. Contrary to this trend, we believe there are reasons in our statistical population to proceed otherwise, that is, to expect randomness on inter-municipal structural differences; therefore, we opt for a stochastic specification of individual effects. A formal test supports, in our case, the superiority of the latter versus the former approach.

The paper is organised as follows. Section 2 sets the theoretical model. Major features of the empirical application, such as sample nature, variable definitions and econometric framework, are explained in Section 3. The main empirical results follow in Section 4. Section 5 concludes.

\section{Electoral Defeats: the Rationale for a PBC}

This section presents the model under which the PBC is driven by the incumbent's concern with her own welfare in case of electoral defeat or, more generally, no re-election. We first describe the assumptions underlying the fiscal policy problem faced by the incumbent politician. Then, we present three theoretical outcomes, one by one: intertemporal consistency of the policy-maker's problem, $\mathrm{PBC}$ on local public expenditure and a comparative static experiment over the PBC width.

\subsection{Assumptions}

Consider two time periods, with an election taking place in-between. ${ }^{4}$ The model addresses institutional set-ups where the government does not have the option of calling for an early contest. The local government's intertemporal budget constraint is

$$
g_{1}+g_{2}=t
$$

\footnotetext{
4 This two-period time segmentation is usual in related literature. See, for instance, Lohmann (1998), Dur et al. (1998), Tabellini and Alesina (1990), Persson and Tabellini (1990) and Alesina and Rosenthal (1988).
} 
where $g_{i}$ stands for expenditure in period $i(i=1,2)$ and $t$ is total revenue. For simplicity, there is no intertemporal discount rate. ${ }^{5}$ In many countries, local governments have a substantially greater discretion over expenditure than over revenue. Moreover, most revenue parameters tend to be determined outside the local tier. ${ }^{6}$ Hence, we take $t$ as exogenous; in the sequel, we normalise it to unity without loss of generality.

An elected politician (the incumbent) runs the government and each office term lasts two time periods. The incumbent decides expenditure levels at the beginning of each period. She derives personal satisfaction from her political activity during each period, $v\left(g_{i}\right)$, and this function is twice continuously-differentiable with $v^{\prime}>0, v^{\prime \prime}<0$ for $i=1,2$. The justification for a utility term associated to holding office can be traced back to the ego-rent label introduced by Rogoff (1990). Explanations for preferring large budgets to small ones, other things being equal, are common in the public choice literature-recall, for instance, the leviathan description of government as made by Brennan and Buchanan (1980, Chs. 2 and 7) or Findlay and Wilson (1984). ${ }^{7}$

The politician enjoys $v g_{2}$ ( only if re-elected, which is an uncertain event. We believe the incumbent does care as well about the prospects of losing her office in the following contest. Hence, this model innovates by looking also at the welfare associated to this latter event. As mentioned above, there is an opportunity cost to holding a public office. Instead of being incumbent, the politician may be active elsewhere in the economy, either in the private sector or in a non-local public sector, and earn income $y$ per period. Let $x(y)$ denote the twice continuously-differentiable utility derived from the outside income, with $x^{\prime}>0$. At the beginning of period 1 , the incumbent faces the intertemporal utility function

$$
u=v \mathbf{I}_{1} !+\pi v \mathbf{I}_{2} \mathbf{!}+(1-\pi) x(y)
$$

\footnotetext{
${ }^{5}$ A positive discount rate was essential to allow for a PBC in many backward-looking models popular in the 1970s. As we are dealing with forward-looking expectations, we can set it aside and still explain a cycle. Of course, a positive discount rate could be introduced in our model without changing results qualitatively. Thus, we opted for its exclusion to stress what is essential.

${ }^{6}$ Local governments naturally have a weaker access to own resources than central governments. This is due to tax base mobility, scale economies in tax administration, compliance costs, and (notably in the case of smaller jurisdictions) lack of administrative capacity. Hence, most revenue is made of grants and taxes whose decisive parameters are set by upper-level governments. For actual illustrations, see Fisher (1996, Chs. 1 and 11) on the US case and Baleiras (1998) and Costa (1996) on the Portuguese case.
}

7 Moreover, politicians' preferences over public outlays underpin the money-metric utility concept of total evaluation function recently introduced by Kraan (1996, Ch. 3) to model the demand for public goods by political authorities. 
where $\pi$ indicates the re-election probability. This probability is endogenously determined by the electorate's ex ante assessment of the incumbent's future performance while in office, which we denote by $s$. So,

$$
\pi=\bar{\pi}+\gamma(s)
$$

where $\bar{\pi}$ represents an exogenous probability component and $\gamma(\cdot)$ is twice continuouslydifferentiable, with $\gamma^{\prime}>0$. We further assume $\pi(s)<1$, i.e., the incumbent never runs unopposed, and $\pi(s) \geq 0$, where the equality allows for the possibility of no re-candidacy; therefore, $-\gamma(s) \leq \bar{\pi}<1-\gamma(s)$. The modelling of $\pi$ thus reflects a democratic political system.

The outside income $y$ is endogenous. The incumbent's fiscal policy decisions are a signal of her competence for prospective employers. The income they are ready to offer her naturally rests on the evaluation they make about her political activity performance, $s$, which is thus shared by the electorate at large and prospective employers in particular. ${ }^{8}$ So

$$
y=y(s)
$$

which is assumed to be twice continuously-differentiable, with $y^{\prime}>0$.

Finally, we must define the way voters and prospective employers assess governmental choices. Taking $g$ as expenditure on public goods, they are naturally pleased whenever their provision is increased and displeased when called to pay for it. Therefore,

$$
s=w \mathbf{g}_{1} !+w \mathbf{g}_{2} !
$$

where $w(\cdot)$ is twice continuously-differentiable, with $w^{\prime}>0, w^{\prime \prime}<0$. Government revenue $t$ is omitted from (5) because it is exogenous. This evaluation function is forward-looking since people at time zero judge the current incumbent according to what they expect her to do in the future. Why would a rational individual ever assign any weight in his voting decision to what a government has done in the past when what matters to him is what the government will do in the future? ${ }^{9}$ Note that prospective employers take into account the incumbent's choice of $g_{2}$ in their assessment, a choice the politician will have to make in the post-election period only if reelected, even though outside employment takes place in the opposite state of the nature (non-reelection). We are thus assuming rational players and perfect foresight. This, in turn, implies that voters' interests do influence the incumbent's choices since the latter incorporates the

\footnotetext{
${ }^{8}$ We may take the latter as a random sample of the former, a reasonable and mild assumption.
} 
electorate's evaluation in her decision problem - directly through $\pi(s)$ and indirectly through $y(s) .{ }^{10}$ There are empirical tests asserting the wisdom of this procedure-see Levernier (1992) for an application to US state government elections.

An appropriate incentive-compatibility constraint is required to make the incumbent politician interested in a re-election run. Condition

$$
\phi \equiv v \mid g_{2} !-x(y)>0
$$

plays this role. It says the utility from being re-elected, $v(\cdot)$, exceeds the satisfaction derived from the alternative occupation, $x(\cdot)$. This expression thus states the expected incentive for the incumbent to seek re-election; it can be understood as a necessary (though not sufficient) condition for a re-election run. It would be unrealistic to suppose the sign of $\phi$ otherwise as the vast majority of incumbents seek re-election if permitted to do so. Technically, a negative $\phi$ would alter the players' incentives implicit in our model, thus rendering its solution meaningless-see Proposition 2 below. It also seems natural to assume $\partial \phi / \partial g_{1} \leq 0$; in words, the lower the pre-electoral public expenditure the higher is the post-electoral (feasible) expenditure and the more willing to accept a second term in office will the current incumbent be. Thus, by taking the intertemporal budget constraint (1) into account when differentiating condition (6), we derive the assumption

$$
v^{\prime} \mid 1-g_{1} !+x^{\prime} y^{\prime}\left[w^{\prime}\left|g_{1} !-w^{\prime}\right|-g_{1} ! \geq 0\right.
$$

To conclude, two further technical assumptions are required if one wants the optimal solution to be meaningful. Basically, we require the incumbent's utility function $u(\cdot)$ to be strictly quasi-concave in $g_{1}$ and $g_{2},{ }^{11}$ and will exclude non-interior solutions in the sequel.

\footnotetext{
Footnotes, continued from previous page

9 Naturally, this attitude does not exclude data on the government's past behaviour from the voter's relevant information set. Further justification for this line of reasoning can be found in Keech (1995, pp. 141-143) and Alesina and Rosenthal (1995, p. 3).

${ }^{10}$ A curious interpretation of voters' rational behaviour is summed-up in three characteristics by Suzuki (1994, pp. 241-242), regarding the design of macroeconomic political business cycle models: "(the) electorate possesses a well-defined utility function in accordance with the structure of the macroeconomic system in which they operate; voters have good ideas about the strategic environment of the system and are aware of the possibility that the incumbent government will pursue its own political goals at the expense of public economic well-being; understanding that the way they evaluate the government profoundly influences the formation of macroeconomic policy, voters rely on a sophisticated heuristic for their electoral judgements in an attempt to hold the government accountable for economic performance."

${ }^{11}$ Quasi-concavity defined for $u(\cdot)$ with $\pi, y$ and $s$ replaced by their definitions so as to have the politician's objective function defined only over the fiscal instruments she controls.
} 


\subsection{The optimal fiscal policy problem}

Under the hypotheses presented in Subsection 2.1, how is local fiscal policy designed? The incumbent's choice of $g_{2}$ is trivial. She maximises her own welfare $v(\cdot)$ by exhausting the budget revenue $(t=1)$, net of the previous period expenditure $g_{1}$, since $v^{\prime}>0$. Thus,

$$
g_{2}=1-g_{1}
$$

The selection of $g_{1}$ is not trivial. The politician maximises her intertemporal utility (2) subject to the constraints resulting from the definitions of re-election probability (3), outside income (4), voters' and prospective employers' assessment of her performance (5), as well as from her own (trivial) strategy for choosing $g_{2}$. Formally, the fiscal problem faced in the preelectoral period is

$$
\begin{aligned}
& \max _{g_{1}, g_{2}} v \mathbf{g}_{g_{1}}\left(+\pi v \mathbf{g}_{2} !+(1-\pi) x(y)\right. \\
& \begin{array}{ll}
\mathbf{R}=\pi(s) \\
\mathbf{\mathbb { \pi }}=y(s) \\
\mathbf{S}_{s}=w\left(g_{1}\right)+w\left(g_{2}\right) \\
g_{2}=1-g_{1}
\end{array}
\end{aligned}
$$

which simplifies to

$$
\begin{aligned}
& \left.\max _{g_{1}} v\right|_{g_{1}} !+\pi\left[\left.w\right|_{g_{1}} \text { ! }+w\left|1-g_{1} \eta_{v}\right|_{1-g_{1}} \mathbf{I}_{+}\right.
\end{aligned}
$$

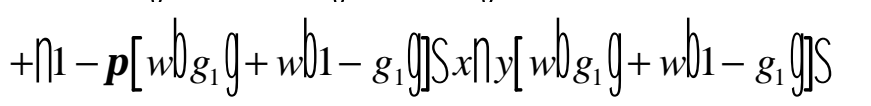

In the pre-electoral period, the incumbent picks $g_{1}$ taking into account how her decision shapes her subsequent policy option, if re-elected. This is clear if we note that the solution to problem (8) is recursively derived and thus constitutes a sub-game perfect Nash equilibrium of the game. We state this first result as Proposition 1.

Proposition 1-optimum and Nash equilibrium: the optimal solution to the local incumbent's problem before elections is a pure strategy sub-game perfect Nash equilibrium of a game played by successive policy-makers.

Proof: see Appendix.

\footnotetext{
12 The re-election probability is still ruled by function (3). The parameter $\bar{\pi}$ is omitted here just to economise on notation. It will play a relevant role in Proposition 3 below.
} 
Proposition 1 assures us that the backward induction procedure used to solve the dynamic fiscal policy game generates a time-consistent expenditure profile no matter who wins the upcoming elections. In case of the incumbent's defeat or no candidacy to a new term, the choice rule of the subsequent administration regarding $g_{2}$ is also to exhaust the budgeted revenue, exactly the same strategy for setting $g_{2}$ as the current incumbent's. ${ }^{13}$

The problem above can also be looked upon as a stage of a multi-stage game where one of the players is a composite of successive administrations, the other two being voters and prospective employers. However, stationarity of the stage game, resulting from the assumptions on the budget as well as on voters' and employers' horizons (two consecutive periods with elections in-between), simplifies the analysis considerably by eliminating the need to study the overall game. Note also that the incumbent has a pre-commitment mechanism since her preelectoral choice renders her post-electoral policy option credibly known to both voters and prospective employers.

\subsection{The political expenditure cycle}

In this subsection, we want to show how a specific intertemporal expenditure asymmetry is generated in an institutional environment as described above. To do that, we must first characterise the optimal solution to problem (8). This characterisation is conveyed by the firstorder condition ${ }^{14}$

$$
\left.v^{\prime}\right|_{g_{1}} \mathbf{l}-\pi(s) v^{\prime} \mathbf{l}_{1-g_{1}} \mathbf{(}=\Omega\left[w^{\prime} \mathbf{l}_{g_{1}} \mathbf{(}-w^{\prime} \mathbf{l}_{1-g_{1}}\right]
$$

with

$$
\Omega \equiv \mathbf{X}[y(s)]-v \mathbf{l}-g_{1} \mathbf{(} \mathbf{\gamma}^{\prime}(s)-[1-\pi(s)] x^{\prime}(y) y^{\prime}(s)<0
$$

The sign of $\Omega$ springs from the incentive condition (6) and the derivative signs assumed over the primitive functions. The following proposition states the political business cycle in our model.

Proposition 2-the political expenditure cycle: the incumbent's optimising behaviour captured by the first-order condition (9) implies a politico-budgetary cycle such that pre-electoral expenditure exceeds post-electoral expenditure $g_{1}>0.5$ !

\footnotetext{
${ }^{13}$ Though in a different policy context, Tabellini and Alesina (1990, p. 40) have pointed out that the time-consistent solutions to dynamic optimisation problems similar to ours is indeed the non-co-operative equilibrium of a game played by consecutive decision-makers.

${ }^{14}$ Its necessity to describe optimal behaviour is established by the proof to Proposition 2, below.
} 
Proof: see Appendix.

So, the incumbent engenders a cycle: at the optimum, $g_{1}>g_{2}$. Why? By taking into consideration the chance of losing the upcoming contest and thus earning the outside income, the incumbent is led to discount future utility from being in office according to her re-election prospects, whereas her pre-electoral utility is not discounted. Hence, pre-electoral outlays bear full marginal utility, whereas, in contrast, post-electoral expenses convey only a probabilistically discounted marginal utility. As a consequence, she is led to set pre-electoral expenditure above post-electoral expenditure. Summing-up, the concern with her own post-electoral welfare, by leading to a probabilistic assessment of post-election outcomes, generates a cycle.

One could note that a pure re-election seeker would induce no cycle at all in this model, which contrasts sharply with the conventional wisdom in the opportunistic PBC literature - see Baleiras (1997) for details. The cycle is clearly ascribed to the contingent nature of the incumbent's post-election utility that results from her concern with the electoral outcome. ${ }^{15}$

\subsection{Re-election probability and the cycle width}

In typical opportunistic political business cycle models, we would anticipate an inverse relationship between the probability of electoral success and the expenditure cycle width. When that probability drops unexpectedly, the re-election-seeker reacts by spending more before elections in order to recover popularity, thus widening the cycle. ${ }^{16}$

In our model, the incumbent is not a pure re-election runner and yet the above relationship still holds. The present subsection aims precisely at showing this (apparently) odd outcome. To consider this issue, we have to look for the total derivative of $g_{1}$ with respect to the exogenous probability component $\bar{\pi}$. As will be shown below, a clear conclusion is achieved. We state it as Proposition 3.

Proposition 3-re-election probability and the political expenditure cycle: the political expenditure cycle does not narrow with declining exogenous re-election probability $\left(d g_{1} / d \bar{\pi} \leq 0\right)$.

Proof: see Appendix.

\footnotetext{
15 Baleiras and Santos $(2000,2001)$ extend this model in a number of ways. In particular, they allow voters and the business community to have independent preferences. Interestingly, even when both groups exhibit an exogenous bias towards "reverse" cycles (i.e., fiscal policies where $g_{1}<0.5$ ), the later paper shows that a cycle such as Proposition 2 predicts is statistically more likely.

${ }^{16}$ As Frey and Schneider (1978) put it: "When (governments) are afraid of losing the election, they make an effort to influence the economy in order to increase their popularity and hence their chances of re-election."
} 
With exogenously given revenue, an increase in pre-electoral expenditure decreases postelectoral expenditure and thus widens the cycle. Proposition 3 tells us that an exogenous probability fall does not shrink the electoral expenditure deviation.

This outcome would be the natural response of a re-election seeker, pure opportunistic politician. However, our model does not comprehend such a player. Intuitively, note that a fall in the exogenous probability of success decreases the weight assigned by the incumbent to postelectoral public expenditure. In fact, recall the objective function (2). Both $g_{1}$ and $g_{2}$ enter the outside income definition with the same weight. However, a given level of $g_{1}$ pays off a higher ego-rent than an equal level of $g_{2}$ because $v\left(g_{2}\right)$ is discounted by the success probability. Hence, a lower probability renders the pre-electoral utility even more important than the postelectoral one. Therefore, the rational incumbent reacts to the probability shock by widening (or, at least, by not narrowing) the expenditure cycle. The discussion of the following example may provide additional motivation for this outcome.

Consider two alternative incumbents, one seeking re-election and the other not. Clearly, the re-election probability is positive in the former case $^{17}$ and nil in the latter. With the specific probability function we are using, it seems natural to differentiate between the two alternative cases according to the value of the exogenous component $\bar{\pi}$. Hence, an incumbent not seeking re-election has a lower $\bar{\pi}$ than an incumbent standing for the next elections. ${ }^{18}$

Recall that Proposition 2 applies to both cases, that is, a political expenditure cycle is predicted whether or not the current incumbent runs for re-election. By definition, someone not standing for re-election has no incentive to manage policy instruments for electoral purposes and so the expenditure cycle to which she contributes is solely motivated by ego-rents on her last office period, which happens to be a pre-electoral period. The re-election seeker, though facing an uncertain contest score, attaches some utility to the victory outcome and so decides to spend public resources more evenly across time. Therefore, a larger public goods provision before elections is naturally expected from the departing incumbent. Furthermore, the quitting incumbent may also want to deliberately damage her successor's expenditure scope, especially if the most likely winner belongs to a different party. These motives all contribute to exhilarating the expenditure cycle when the current incumbent does not aim for re-election.

\footnotetext{
${ }^{17}$ We naturally discard the possibility of an absolute incompetent politician for whom the chances of being reelected are simply non-existent.

18 More precisely, the no re-candidacy case implies $\bar{\pi}=-\gamma(s)$ in equation (3), exactly the lower bound for parameter $\bar{\pi}$. The re-candidacy case implies $\bar{\pi}>-\gamma(s)$.
} 


\section{Application to Portuguese Municipalities}

As an application of the previous theoretical work, we now wish to investigate whether the proposed structural model helps to understand the actual behaviour of local governments in Portugal. Propositions 2 and 3 contain empirical implications that make up the basic ingredients to test. The former implies that pre-election local government expenditure exceeds post-election local government expenditure. The latter entails a cycle to a departing incumbent that is at least as large as the one induced by a re-election seeker politician. Note that this second implication discriminates on empirical grounds our rationale from a conventional opportunistic model because, in such a model, the incumbent cannot aim at anything other than winning the forthcoming electoral contest. Through this application, we also hope to enlighten other potentially interesting facts concerning the political economy of Portuguese local public finance. We first introduce some institutional information that is relevant for empirical modelling; secondly, we describe the data set; thirdly, we explain the econometric framework designed to serve the above purposes.

\subsection{An institutional digest of investment-decision making in Portugal}

For reasons to be explained in the next subsection, investment outlays are the expenditure category that will matter to us the most in this application. A few institutional facts regarding local investment setting seem useful to appraise the empirical modelling options described below. The local government unit we will address here is the municipality. In mainland Portugal, the public sector comprises the central government and 278 municipalities-there are no intermediate-level governments. Each year, the municipality's executive branch proposes to the legislative branch the local budget and the activities plan. The legislative branch votes on both documents but cannot impose any amendment to them. Investment expenditures can only be authorised whenever they are budgeted and framed in the activities plan.

A wide public investment spectrum is legally foreseen for local governments' intervention. Municipalities hold exclusive competencies to promote investment on particular items in the following areas: urban and rural facilities, sewerage, energy, transports and communications, education, culture-leisure-sports and health. Through case-by-case partnership contracts with the central government, the municipality may also invest in other areas along regulated sharing procedures.

The chairman/woman of the executive branch (presidente) plays a prominent role in bcal politics. Moreover, she is legally assigned protagonist functions as far as investment actions are concerned. Among her exclusive capacities, she is entitled to the right to personally authorise the payment of budgeted outlays and the execution of public works framed in the activities plan. In other words, she hold alone the power to decide on the timing of local investment actions and on the choice of capital goods suppliers. 
The sensitivity of citizens' daily life to municipal investment assignments and the protagonism legally vested in the executive branch leader we have just seen suggest that she has the means required to implement the political budget cycle modelled in Section 2. It is now up to the rest of this paper to demonstrate that she also behaves according to the modelled will.

\subsection{The sample}

We have constructed an annual panel data sample of thirty Portuguese (mainland) municipalities comprising five full electoral terms, from 1977 to 1993. For our purposes, the dependent variable should be an expenditure item having local accountability and political visibility. In other words, the endogenous variable ought to be an expenditure category subject to discretionary change by the local authority and whose manipulation from one period to another is not constrained by serious rigidities; additionally, people's awareness about these outlays is crucial if one expects governments to use them to enhance their idiosyncratic goals. For example, wage payments to local civil servants are not a good candidate for dependent variable in most countries both because public employment flexibility is not symmetric (entries tend to be easier than exits) and labour contracts do not provide the kind of inter-year wage flexibility deemed necessary to allow for political business cycles. The political visibility of wage outlays can be significant in small jurisdictions where the local authority accounts for a large employment share but this is not the dominant pattern in most countries.

In our application, the dependent variable (denoted by $y$ ) is total real per capita investment expenditure: if any political influence of the kind discussed in Section 2 exists, investment is the expenditure item over which that influence is likely to extend with greater significance.

The empirical test of Propositions 2 and 3 requires the use of qualitative explanatory variables. Given the two-period nature of the incumbent's model discussed in Section 2, it seems natural to define the two following dummy regressors:

$$
\begin{aligned}
& x_{2}=\$ \frac{5}{7} \text { if local elections are held at the end of the current period } \\
& x_{3}=\$_{0} \begin{array}{l}
\text { if the current incumbent seeks re-election and } \\
\text { otherwise }
\end{array}
\end{aligned}
$$

\footnotetext{
${ }^{19}$ Variable $x_{1}$ has unit value if the regression equation contains an intercept term. More will be said about the intercept presence later on when presenting the estimation method.
} 
According to our economic model, elections are run in (at the end of) the second period of each office term. Consider a fit involving $x_{2}$ only. Our prior, based on Proposition 2, is to find a positive estimate of $\beta_{2}{ }^{20}$ The electoral schedule introduces an expansionary deviation on investment outlays at pre-electoral periods. If $x_{2}$ and $x_{3}$ enter the same fit, Proposition 2 calls for positive estimates of $\beta_{2}$ and $\beta_{2}+\beta_{3}$ because a PBC is expected without regard to the outcome of the re-candidacy decision. However, this decision is expected to make a difference on the cycle width; in fact, Proposition 3 implies $\beta_{3} \leq 0$, thus ascribing a narrower cycle to a reelection seeker.

Due to a legislative change, the first three sample terms (1977 to 1985) are three years long and the last two (1986 to 1993) are four years long. The pre-electoral period of these latter terms was defined as the election's year and the year before; the pre-electoral period of the former was defined as the election's year only.

We have defined an additional political regressor to take into account the degree of political cohesion within the local government. Although the theoretical model of Section 2 does not require this variable, we believe it plays an interesting role in actual policy-making; hence, we decided to include it in the current application. ${ }^{21}$ In Portugal, as in many other countries, the budgetary function is shared between both branches of government but naturally, the intertemporal profile of fiscal policy is a prerogative of the branch empowered with the initiative competence. $^{22}$ Thus, municipal parliaments are not so bothered with intra-tenure investment management as are executive branches and their leaders. They do, however, believe in the political value of investment outlays. Hence, the members of a local parliament belonging to the president's party naturally tend to favour expansionary plans while their opponents wish to restrain investment initiatives. To make it clearer: ceteris paribus, we expect municipal investment in any year to be higher if the president's party enjoys an absolute seat majority at the legislative branch than when that is not the case. We can test for this hypothesis by defining a new political dummy variable,

$$
x_{4}=\$ \begin{aligned}
& \text { if the incumbent's party holds more than } 50 \% \text { of total seats } \\
& \text { at the legislative branch } \\
& \text { otherwise }
\end{aligned}
$$

\footnotetext{
${ }^{20}$ Hereinafter, we will denote the parameter associated to the independent variable $x_{k}$ as $\beta_{k}$.

${ }^{21}$ Actually, the fits do improve with the presence of this variable.

22 This prerogative is indeed legally binding in Portugal. According to the Local Authorities Act, the municipal parliament cannot introduce a single amendment to the budget or the activities plan proposed by the executive branch; it can only approve or reject the executive's proposal (no. 4 of article 39).
} 
Our expectation is therefore to find a positive estimate of $\beta_{4}$. We could alternatively conceive a continuous measurement of political cohesion, defined by the exact seat percentage. However, this seems a rather weaker way of capturing econometrically the likely influence of political cohesion. A score under 50 per cent would probably call for a compromise solution with other parties at the parliament, thus diluting the expansionary motivation of the ruling party.

There is one last explanatory variable we need to define. An economic variable is required to control the regressions. As the financial environment facing local governments is not stabilised along the sample period, we must distinguish between expenditure changes genuinely induced by local political considerations and expenditure changes simply due to varying funding. Therefore, we should add a funding indicator to the empirical model in an attempt to control for political effects. Received capital transfers are a natural candidate, given their relative sizethese grants represent over 60 per cent of capital accumulation during the sample period. We label this new variable as $x_{5}$. It is obviously defined in real per capita units, just like the dependent variable. Naturally, we expect a positive estimate for $\beta_{5}$.

In principle, we could instead use lagged values of the dependent variable to control the regressions. In fact, this alternative approach has been endorsed in several papers, such as Blais and Nadeau (1992) and Alesina and Roubini (1992)—who have both used the first three lags. However, these authors have all benefited from much longer (time) samples. ${ }^{23}$ In our case, lagging the dependent variable would reduce the time dimension too severely, as we have only seventeen periods and five full government terms.

To conclude, we add a word on the technical measurement of the economic variables. As there is no theoretical recommendation, our empirical implementation will measure real per capita investment and real per capita transfers both in natural units and in logarithmic terms. However, for the sake of space, we report only the logarithmic case in Section 4 below, as its fits are better.

\subsection{The econometric framework}

As is evident from the sample nature discussed above, each variable observation contains both an individual and a time dimension. With $N$ individuals and $T$ time periods, the empirical model becomes

$$
y_{i t}=\sum_{k=1}^{K} \beta_{k} x_{k i t}+v_{i t} \quad i=1, \ldots, N ; t=1, \ldots, T
$$

\footnotetext{
${ }^{23}$ For example, Blais and Nadeau considered annual data from 1951 to 1984 (34 periods) and Alesina and Roubini managed quarterly data from 1960 to 1987 (112 periods).
} 
where $k$ accounts for the number of regressors and $v_{i t}$ is the usual stochastic residual. Sample municipalities are likely very different from one another. Population size is not the same across them, their geographic location varies, they are ruled by distinct political parties, the personal motivation of incumbent leaders is inherently idiosyncratic, incumbents' competence is unalike and all this diversity leads local governments to differ in the way they adjust investment expenditure to common stimuli. Clearly, the assumption of equal regression coefficients implicit in (10) does not seem realistic. But the problem of finding a better specification is that we do not know for sure what it exactly is. Moreover, the wish to add realism must be traded off against the degrees of freedom loss when we think about estimation procedures.

In our quest for a parsimonious specification allowing for individual heterogeneity, we decided to reflect inter-municipal differences solely in intercept terms. To be more precise, all slope coefficients are assumed to be equal across individuals and the parameter associated to $k=1$ is expressed as

$$
\beta_{1 i t}=\beta_{1}+\mu_{i} \quad \forall i, t
$$

where $\beta_{1}$ is constant and $\mu_{i}$ is the individual-specific component. Although unknown, one must also assume from the outset whether these individual components are fixed or random.

The choice between fixed and random effect specifications has been thoroughly analysed in the econometrics literature. Following several criteria suggested by Balestra (1992), Hsiao (1986, Chs. 3 and 6; 1992) and Greene (1993, Sc. 16.4), we opt for the stochastic version of individual parameters. First, municipal heterogeneity lies upon a number of non-observable random causes, such as access to capital transfers, ${ }^{24}$ incumbent's re-candidacy decision ${ }^{25}$ or reelection probability. ${ }^{26}$ Secondly, given that $T$ is relatively small (when compared to $N$ ) in our sample, parameter estimates in fixed-effect models are less reliable than in random-effect models because the ratio of estimable coefficients to available observations is larger. Thirdly, the sample is open in the sense that the $N$ collected municipalities are only a subset of the whole statistical

\footnotetext{
${ }^{24}$ Access to national transfers relies very much on the central government's discretion and very little on the local governments' behaviour. The same applies to European capital grants, whose eligibility is contingent upon administrative contests empowered by the central government and European agencies. Ex ante, these variables are unknown to the individual municipality, whose bargaining power is typically too small to exert any noticeable influence upon their realisation. Only a collective lobbying organisation encompassing a large enough number of local governments may have such power. The reader interested in a political economy approach to municipal lobbying for transfers may wish to consult Pereira (1996).

25 The re-candidacy decision, whose foundations lie beyond this essay's scope, depends on the incumbent's personal trade-off between the local public and non-local public job offers and we can think of politicians as being sorted out from a random distribution of these trade-offs. The concerned reader can refer to Reed (1994) for a cost-benefit analysis of re-election runs.

${ }^{26}$ We have not explored in Section 2 the randomness of the re-election probability but we do not ignore its role in the real world. See Tabellini and Alesina (1990) for an example of random probability modelling.
} 
population of Portuguese local governments. Therefore, individual differences are not a main research concern - the focus is clearly on slope parameters. Individual asymmetry analysis would become a natural priority if the sample were closed in the sense of covering all individuals of the statistical population; in this case then a fixed-effects model would be most welcome. ${ }^{27}$ Finally, we would like to use regression results to draw conclusions bearing some significance $\mathrm{b}$ Portuguese local public finance in general and not only applicable to sampled municipalities. In other words, we prefer to make statistical inference with respect to population features rather than inference conditional on the effects present in the sample. According to Hsiao (1986, Chs. 3 and 6) in particular, a random-effects model is the most suitable specification when this kind of inference is wished. ${ }^{28}$

Having decided to use a stochastic specification of individual effects on intercepts, the appropriate econometric specification is the so-called error-components model. It will be estimated according to the feasible generalised least-squares method. Technical details on both the model and the estimator can be found, for example, in Greene (1993, Ch. 16), Mátyás (1992) and Hsiao (1986, Ch. 3).

\section{Empirical Results}

We are finally able to report the main outcomes of our empirical research. The basic results are in Subsection 4.1 while a refinement comes in Subsection 4.2.

\subsection{Basic evidence}

The relevant results are shown in Table 1 . The regression in column $1^{29}$ is the benchmark case: it runs the logarithm of real per capita investment expenditure (y) against the logarithm of real per capita received capital transfers $\left(x_{5}\right)$ and the political dummies (the electoral variable $x_{2}$, the re-candidacy differential variable $x_{3}$ and the political cohesion variable $x_{4}$ ). The fitted line seems quite good. In fact, all parameter estimates are economically sound since they conform to the predictions designed in Sections 2 and 3. Moreover, most results bear statistical significance.

\footnotetext{
${ }^{27}$ The individual-specific terms $\mu_{i}$ should be treated as constants if the performance of the individual units in the database were of paramount interest, but that is not our case. The size and magnitude of slope coefficients matter more for us than eventual individual differences between them.

${ }^{28}$ On top of all these theoretical arguments in favour of the random-effects model, an appropriate statistical test clearly endorses our choice-Hausman's test, see results below.

${ }^{29}$ Tables in this paper are interpreted from left to right. Hence, column 1 always refers to the leftmost displayed regression.
} 
Leaving Propositions 2 and 3 for a later comment, note that the parameter estimate associated to the political cohesion dummy is positive, as expected, and statistically significant. The control variable role is very strong; the elasticity of investment with respect to received capital transfers is about 68 per cent, displaying a remarkable statistical significance. The specification passes the overall significance $F$-test, despite the fact that its coefficient of determination is only about 51 per cent. ${ }^{30}$ Interestingly, the Hausman's statistic is comfortably located in the acceptance region of the relevant $\chi^{2}$-distribution (the critical value for a 99 per cent confidence level is 13.3); thus, the empirical evidence does not contradict our priors in favour of the random composition of individual effects.

Table 1-The PBC on local investment expenditure, 1977-1993

\begin{tabular}{|c|c|c|}
\hline $\begin{array}{c}\text { Independent } \\
\text { variables }\end{array}$ & $\begin{array}{c}\text { Dep. var. } \\
\ln y\end{array}$ & $\begin{array}{c}\text { Dep. var. } \\
\ln y\end{array}$ \\
\hline $\ln x_{5}$ & $\begin{array}{c}0.677 \\
(10.667)^{*}\end{array}$ & $\begin{array}{c}0.701 \\
(11.176)^{*}\end{array}$ \\
\hline$x_{2}$ & $\begin{array}{c}0.223 \\
(2.142)^{* * *}\end{array}$ & - \\
\hline$x_{3}$ & $\begin{array}{c}-0.099 \\
(-0.877)\end{array}$ & - \\
\hline$x_{4}$ & 0.265 & $\begin{array}{c}0.257 \\
(3604) *\end{array}$ \\
\hline Constant & $\begin{array}{c}0.975 \\
(5.135)^{* *}\end{array}$ & $\begin{array}{c}0.987 \\
(5.220)^{* *}\end{array}$ \\
\hline $\begin{array}{l}\text { St. error of } \\
\text { regression }\end{array}$ & 0.339 & 0.345 \\
\hline$R^{2}$ & 0.513 & 0.487 \\
\hline Adjusted $R^{2}$ & 0.471 & 0.451 \\
\hline Hausman & 5.315 & 5.354 \\
\hline \multicolumn{3}{|c|}{$\begin{array}{l}t \text {-Ratios in parentheses. } \\
* \text { Significant at } 99 \% \text { (one-tailed test). } \\
* * \text { Significant at } 99 \% \text { (two-tailed test). } \\
* * * \text { Significant at } 97.5 \% \text { (one-tailed test). }\end{array}$} \\
\hline
\end{tabular}

We can now address the empirical implications of our main theoretical results. Recall that Proposition 2 entails $\beta_{2}>0$ and $\beta_{2}+\beta_{3}>0$ while Proposition 3 implies $\beta_{3} \leq 0$. As mentioned above, the estimates in column 1 do comply with these theoretical restrictions. According to them, leaving incumbents are associated to a 22 per cent investment jump in pre-electoral years while re-election runners also display an intertemporal asymmetry but of a lesser magnitude, recording only a 12 per cent PBC. Chart 1 illustrates the cycle for the case of the Loulé municipality. ${ }^{31}$

\footnotetext{
${ }^{30}$ Typically, panel data models of government finance exhibit relatively low values for $\square$ and display significance problems with dummy variables at high levels of breakdown.

${ }^{31}$ The choice of municipality is immaterial. Loule is located in the Algarve province-southern Portugal.
} 
The solid line plots the no-cycle prediction for this municipality-it corresponds to column 1's fit without the cycle dummies $x_{2}$ and $x_{3}$. Adding up these dummies, we derive the expenditure prediction in line with the proposed regression; its plot is given by the dashed line. Please note that elections were held in mid-December of the following years: 1979, 1982, 1985, 1989 and 1993. The vertical solid line segments between those two lines underline the estimated pre-electoral upward jumps in investment. The jumps are higher ( 22 versus 12 per cent) when the incumbent leader did not run for re-election, which occurred in 1982 and 1985 in the case of Loulé.

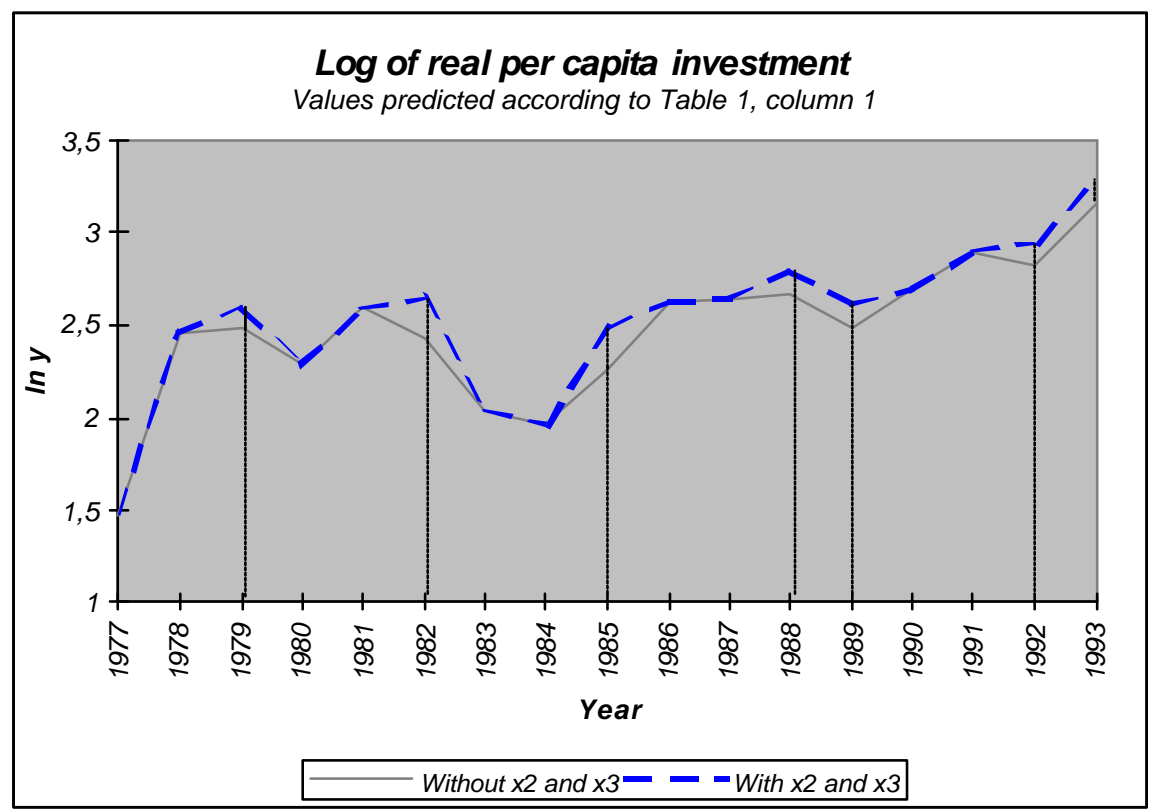

Chart 1-The political expenditure cycle in the municipality of Loulé

The statistical significance of investment deviations was also investigated. First, we tested for the joint significance of both propositions. Column 2 in Table 1 presents the constrained model (derived from column 1 by imposing the nulls). The relevant $F$-statistic is $13.465,{ }^{32}$ and so the data do not reject the overall explanation of investment cycles advanced in Section 2 .

Second, we have also looked for the individual significance of each proposition. As there are two empirical implications springing from Proposition 2, its test requires i) a simple $t$-ratio

\footnotetext{
${ }^{32}$ This statistic is

$$
F=\frac{\mid R^{2}-R_{c}^{2}(/ M}{\text { D } R^{2} g_{N T-K)}}
$$
}

where $M$ is the number of (linear) constraints and $R^{2}\left(R_{c}^{2}\right)$ denotes the coefficient of determination of the unrestricted (constrained) model. It is distributed as $F(M, N T-K)$. 
analysis of $\hat{\beta}_{2}$ in column 1 above and ii) a comparison between the unrestricted model in column 1 and a constrained model embodying the null $H_{0}: \beta_{2}+\beta_{3}$. Note therefore that $\beta_{2}$ in column 1 is significantly non-zero; the coefficient of determination of the constrained model (not shown) is 0.498 , leading to an $F$-statistic of 14.724 , which allows us to reject the null. So both empirical implications of Proposition 2 pass the data test. To est for Proposition 3's implication alone, it is sufficient to look for the individual significance of $\beta_{3}$ in column 1. Although portraying an economically sound estimate, this proposition seems to lack statistical support.

A major event occurred by the middle of the sample period, the country's accession to the (then) coined European Economic Community. As detailed below, this seems a good reason to expect a structural change in the empirical specification around 1986. We therefore decided to test for it and amend our results accordingly. The matter is pursued in the following subsection.

\subsection{Diachronic structural break in 1986}

Portugal joined the European Community as of the $1^{\text {st }}$ of January, 1986. Its participation on the community regional policy gave the central as well as local governments new resources, the structural funds (and later, from 1993 onwards, the cohesion fund). These proceedings are matching grants conditional upon the rules of eligibility and additionality that estrict their use to investment finance. A large fraction is actually translated into public capital accumulation. Rules of access to these new income streams, however, differ quite substantially from those applying to traditional central government transfers. In particular, their disposal by municipal budgets is less predictable than older transfers (those from the central government) since these newer transfers are conditional on the pre-existence of investment programs and, to a large extent, must be bargained with central government agencies. The whole transfer procedure is thus longer and contains several critical deadlines sharing nothing with local electoral schedules. Therefore, we should suspect that the increasing reliance of local governments on structural funds makes the political business cycle harder to implement. Nevertheless, the increasing availability of this new revenue, which does not crowd-out any previous income source, is expected to enhance the power of capital transfers to explain municipal investment.

To test for the potential 1986 break, we divided the sample into two sub-periods, 1977 to 1985 and 1986 to 1993. The results are reported in Table 2, where column 1 repeats column 1 of Table 1 for the reader's convenience.

The evidence in favour of this break is indeed quite strong. There is a clear regression improvement from 1986 onwards. This is perceived by the individual explanatory power of each independent variable and, most noticeably, is reflected in both overall goodness-of-fit statistics displayed: the absolute error measure given by the residual's standard deviation falls from 0.40 to 0.24 and its relative error counterpart, the coefficient of determination, rises almost twenty percentage points. The implicit Chow's test confirms the significance of the differences. The 
residual sum of squares attached to the post-1986 regression is 3.356 while the homologous figure relating to the whole sample period is 16.046; hence, the relevant $F$-statistic is 3.291 , comfortably above the 1 per cent significance threshold. Consequently, we should reject the explicit null hypothesis, that is, we find evidence in favour of a structural break in 1986. The sub-samples are drawn from different populations and so, contrary to our procedure in Subsection 4.1, we should not merge them.

Table 2-Structural break in 1986

\begin{tabular}{|c|c|c|c|}
\hline \multirow{2}{*}{$\begin{array}{c}\text { Independent } \\
\text { variables }\end{array}$} & \multicolumn{3}{|c|}{ Dependent variable: $\ln y$} \\
\hline & 1977-93 & $1977-85$ & 1986-93 \\
\hline $\ln x_{5}$ & $\begin{array}{c}0.677 \\
(10.667)^{*}\end{array}$ & $\begin{array}{c}0.607 \\
(6.168)^{*}\end{array}$ & $\begin{array}{c}0.671 \\
(25.529)^{*}\end{array}$ \\
\hline$x_{2}$ & $\begin{array}{c}0.223 \\
(2.142)^{* * *}\end{array}$ & $\begin{array}{c}0.266 \\
(2.143)^{* * *}\end{array}$ & $\begin{array}{c}0.090 \\
(4.954)^{*}\end{array}$ \\
\hline$x_{3}$ & $\begin{array}{c}-0.099 \\
(-0.877)\end{array}$ & $\begin{array}{c}-0.157 \\
(-0.994)\end{array}$ & $\begin{array}{c}-0.056 \\
(-2.993)^{*}\end{array}$ \\
\hline$x_{4}$ & $\begin{array}{c}0.265 \\
(3.643)^{*}\end{array}$ & $\begin{array}{c}-0.108 \\
(-0.694)\end{array}$ & $\begin{array}{c}0.321 \\
(9.902)^{*}\end{array}$ \\
\hline Constant & $\begin{array}{c}0.975 \\
(5.135)^{* *}\end{array}$ & $\begin{array}{c}1.187 \\
(5.201)^{* *}\end{array}$ & $\begin{array}{c}1.019 \\
(2.993)^{* *}\end{array}$ \\
\hline $\begin{array}{l}\text { St. error of } \\
\text { regression }\end{array}$ & 0.339 & 0.396 & 0.238 \\
\hline$R^{2}$ & 0.513 & 0.379 & 0.563 \\
\hline \multicolumn{4}{|c|}{$\begin{array}{l}t \text {-Ratios in parentheses. } \\
\text { Column 1's fit is column 1's fit of Table } 1 . \\
* \text { Significant at } 99 \% \text { (one-tailed test). } \\
* * \text { Significant at } 99 \% \text { (two-tailed test). } \\
* * * \text { Significant at } 97.5 \% \text { (one-tailed test). }\end{array}$} \\
\hline
\end{tabular}

Interestingly, the cycle width associated to departing incumbents is almost 27 per cent in the first sub-period and declines to only 9 per cent after 1986. Re-election seekers induce an upward jump of about 11 per cent in the first three tenures, with just a 3 per cent cycle thereafter. The elasticity of investment with respect to capital transfers increases from less than 61 per cent in the first period to over 67 per cent afterwards and this point estimate change is combined with a clear significance improvement. A larger and more significant contribution of political cohesion to investment expenditure emerges in recent years.

The reader may also note that all empirical implications of Propositions 2 and 3 bear statistical significance from 1986 onwards. ${ }^{33}$ Therefore, the insufficient statistical background of

\footnotetext{
${ }^{33}$ The coefficients associated to $x_{2}$ and $x_{3}$ are significantly non-zero in column 3 . The same applies to their sum. In fact, the coefficients of determination for the 1986-93 sub-period are 0.563 in the unconstrained equation and 0.513 in the constrained line (not shown) and they entail an $F$-statistic of 27.099, well above the 99 per cent confidence level threshold.
} 
the latter that underlies the mis-specified fit of column 1 is ascribed to the initial period (column 2).

All these figures associate economic plausibility to statistical significance, and two conclusions thus emerge. On the one hand, Propositions 2 and 3 are fully supported by the results in column 3 , thus revealing an actual case where the political business cycle rationale put forward in Section 2 is empirically relevant. On the other, the available data suggest a diachronic structural break: participation in the common regional policy from 1986 onwards may have led to a mitigation of the PBC and a reinforcement of the explanatory power of capital transfers.

\section{Concluding Remarks}

Conventional views about opportunistic PBCs often ascribe their origin to the electorate's shortsightedness or the incumbent's desire to being re-elected. This explanation looks spurious either because agents are not rational or the decision-maker ignores a relevant state of nature, the electoral defeat. Hence, PBCs get interpreted as an odd outcome, incompatible with either rationality or standard microeconomic foundations. In this paper, we suggest a quite different interpretation. PBCs can indeed be the optimal outcome of a ultrarational set-up where voters are forward-lookers and the current incumbent explicitly allows for her satisfaction in the two possible future states of nature: electoral victory and electoral defeat. To the extent that the analysis addresses how the voting institution aligns people's preferences with the incentives of self-interested politicians, the paper is very much in the spirit of the on-going literature on the micropolitical foundations of public finance analysis—see Persson et al. (1998).

The theoretical framework points out three predictions. First, the expenditure profile is time-consistent regardless of who wins the following elections; indeed, the optimal solution corresponds to the (unique) sub-game perfect Nash equilibrium of a game played by successive administrations. Secondly, the optimal policy is a PBC where public outlays before elections exceed those after elections. The incumbent's pre-electoral utility is totally derived from being in office whereas her post-electoral utility is contingent upon the electoral score; hence, consideration for the possibility of defeat (or no re-candidacy) and the concomitant alternative employment introduces an asymmetry in the way pre-and post-electoral expenditure levels are set and engenders the cycle. Thirdly, a decrease in the (exogenous) re-election probability does not narrow the expenditure cycle. This result is at odds with conventional modelling. It arises because the incumbent's pre-electoral utility becomes relatively more important after the probability shock.

We believe the theoretical framework suits particularly to explain PBCs at the local government tier. Thus, the paper has also provided an empirical test to the proposed rationale, based on a panel data sample of Portuguese municipalities. Municipal investment expenditure was the endogenous variable over which political cycles were expected to materialise. The 
empirical evidence seems to support the theoretical model as its predictions were not contradicted by the data, namely in the period 1986-1993.

So, public expenditure fluctuations can be interpreted as the outcome of rational behaviour by fully informed agents. Inasmuch as these fluctuations are regarded as detrimental to society, our research motivates a future study on incentive design to minimise their occurrence.

\section{Appendix}

Proof of Proposition 1: Problem (8) is the recursive solution to the successive static optimisation problems stated in Subsection 2.2. Each static problem can be viewed as a sub-game of a game played by two consecutive administrations. Note that only one action is possible at each moment and that the optimal solution to each static problem is unique; hence, the game at issue belongs to the class of finite games of perfect information. By Zermelo's theorem, we are told that: i) there is a unique Nash equilibrium for the intertemporal fiscal policy game; ii) this equilibrium outcome can be derived through backward induction. Moreover, as with every game in that class, ours has a unique pure strategy sub-game perfect Nash equilibrium-according to proposition 9.B.2. in Mas-Collel et al. (1995, p. 276). Consequently, the strategy profile derived by backward induction in Subsection 2.2 identifies the Nash equilibrium for both the whole game and each associated sub-game.

Proof of Proposition 2: A three-step approach is used to establish the thesis. First, the very existence of an optimal solution is ensured; secondly, the necessity of the first-order condition to describe optimising behaviour is asserted; finally, the specific cycle $g_{1}>0.5$ shall be derived as an implication of the first-order condition.

(i) Optimum existence: the incumbent's problem (8) can be rewritten as

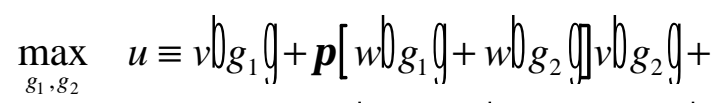

$$
\begin{aligned}
& + \text { ก- } \pi\left[{ }_{w} \mathrm{bg}_{w} \mathrm{~b}_{2} \$ \mathrm{x}_{w} \mathrm{bg}_{w} \mathrm{~b} \Phi\right. \\
& \text { s.t. } \quad \mathbf{Q}_{1}, g_{2} \mathbf{g} E
\end{aligned}
$$

where

$$
E=\mathbf{I} g_{1}, g_{2} ! \mid g_{1}, g_{2}\left(\in \mathfrak{R}_{+}^{2} \wedge g_{1}+g_{2} \leq 1 \mid\right.
$$

is the opportunity set. Clearly, $E$ is a non-empty and compact set in $\mathfrak{R}^{2}$. The objective function is continuous in this set as it is arithmetically built from the continuous function defined therein. Hence, the Weiertrass's theorem applies. Moreover, the optimal solution is unique because the objective function is assumed to be strictly quasi-concave in that domain. 
(ii) Necessity of the first-order condition: condition (9) is necessary to characterise local extrema because both the objective and the constraint are $C^{2}$-functions and the relevant rank condition is obviously met.

(iii) Expenditure cycle: from (i) and (ii) above, we know that a utility maximising basket exists, is unique and verifies (9). We will show now that the optimal solution implies $g_{1}>05$ by contradiction. Suppose $g_{1} \leq 0.5$. Then,

$$
\left.v^{\prime}\right|_{g_{1}}\left(\geq v^{\prime}\left|1-g_{1} \mathbf{l}>\pi(s) v^{\prime}\right| \mathbf{l}-g_{1} !\right.
$$

because $v^{\prime}>0, v^{\prime \prime}<0$ and $\pi(s)<1$. Hence,

$$
v^{\prime}\left|g_{1} !-\pi(s) v^{\prime}\right| 1-g_{1} \mathbf{l}>0
$$

i.e., the left-hand side of (9) is strictly positive. By the same token, $w^{\prime}>0$ and $w^{\prime \prime}<0$ imply $\left.w^{\prime}\right|_{g_{1}}\left(-w^{\prime} \mid-g_{1}(\geq 0\right.$. Since $\Omega<0$, the right-hand side of (9) is non-positive-hence a contradiction is generated when $g_{1} \leq 0.5$. Therefore, $g_{1}>0.5$ in the maximising basket.

Proof of Proposition 3: First, we will derive the bordered hessian determinant associated to the incumbent's problem. Second, the expression for $d g_{1} / d \bar{\pi}$ will be obtained out of the total differentiation of the first-order condition. The sign of this expression follows from that determinant.

(i) The bordered hessian determinant inherent to the incumbent's problem (11) is (interior solutions only)

$$
|\bar{H}|=\left|\begin{array}{ccc}
\ell_{11} & \ell_{12} & 1 \\
\ell_{21} & \ell_{22} & 1 \\
1 & 1 & 0
\end{array}\right|,
$$

where $\ell_{i j}(i, j=1,2)$ denotes the second-order partial derivatives of the auxiliary lagrangean function:

$$
\begin{aligned}
& \left.\ell_{11}=\left.v^{\prime \prime}\right|_{g_{1}} \text { !+[v } \lg _{2} \boldsymbol{\gamma}^{\prime}+(1-\pi) x^{\prime} y^{\prime}-x \gamma^{\prime}\right]\left.w^{\prime \prime}\right|_{g_{1}} !_{+} \\
& +\left\{\dot{Q}_{2} \mathbf{y}^{\prime}+(1-\pi)\left[x^{\prime} y^{\prime \prime}+x^{\prime \prime} \boldsymbol{Q} \mathbf{Q}_{-2 x^{\prime} y^{\prime} \gamma^{\prime}-x \gamma^{\prime \prime}}\right\} v^{\prime} \boldsymbol{Q} \Phi\right. \\
& \ell_{12}=\ell_{21}=v^{\prime} \lg _{2}\left(w^{\prime} \mid g_{1} \boldsymbol{\gamma}^{\prime}+\right.
\end{aligned}
$$

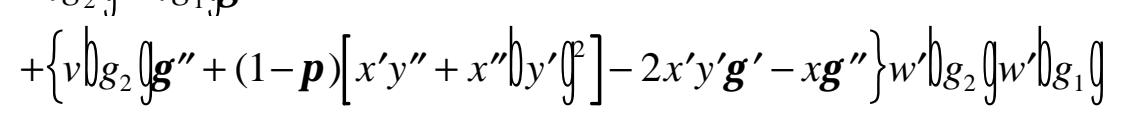




$$
\begin{aligned}
& \ell_{22}=\pi v^{\prime \prime} \mid g_{g_{2}}\left(+2 v^{\prime}\left|g_{2} ! w^{\prime}\right| g_{2} \boldsymbol{\gamma}^{\prime}+\left.\left[\left.v\right|_{g_{2}} \boldsymbol{\gamma}^{\prime}+(1-\pi) x^{\prime} y^{\prime}-x \gamma^{\prime}\right] w^{\prime \prime}\right|_{g_{2}} !_{+}\right. \\
& +\left\{g_{2} \mathbf{y}^{\prime}+(1-\pi)\left[x^{\prime} y^{\prime \prime}+x^{\prime \prime} \boldsymbol{Q}-2 x^{\prime} y^{\prime} \gamma^{\prime}-x \gamma^{\prime \prime}\right\} w^{\prime} Q_{2} \Phi\right.
\end{aligned}
$$

We are interested in evaluating $|\overline{\boldsymbol{H}}|$ at the stationary point, which naturally complies with the budget constraint $g_{2}=1-g_{1}$. After some rearrangements, the determinantal expression becomes

$$
\begin{aligned}
& |\overline{\boldsymbol{H}}|=-v^{\prime \prime} \mid g_{1} \mathbf{l}\left(-\pi v^{\prime \prime} \mid \mathbf{1}-g_{1} \mathbf{l}+\Omega\left[w^{\prime \prime} \mid g_{1}\left(+w^{\prime \prime} \mid \mathbf{1}-g_{1} \mathbf{l}-\right.\right.\right.
\end{aligned}
$$

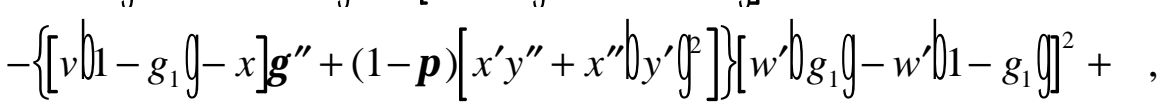

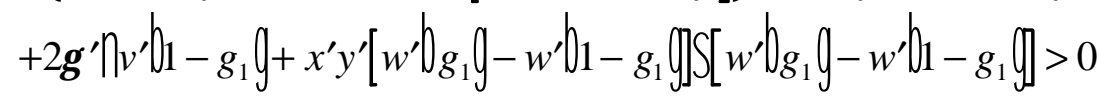

where the strict positiveness follows from the strict quasi-concavity of the objective function in problem (8).

(ii) We now derive $d g_{1} / d \bar{\pi}$. Total differentiation of the first-order condition (9), p. 8, with respect to $g_{1}$ and $\bar{\pi}$ leads to

$$
\begin{aligned}
& \left|v^{\prime \prime}\right| g_{g_{1}}\left(+\pi v^{\prime \prime} \mid 1-g_{1}\left(-\Omega\left[w^{\prime \prime} \mid g_{1}\left(+w^{\prime \prime} \mid 1-g_{1}\right] \mathbf{C}_{d g_{1}-}\right.\right.\right.
\end{aligned}
$$

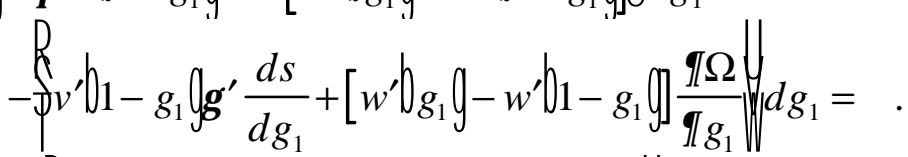

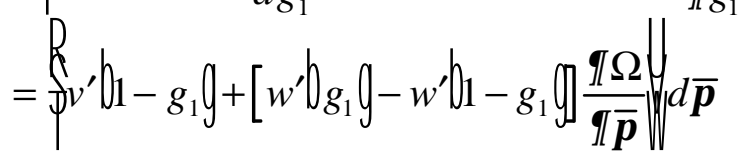

Proceeding to a separate evaluation of the derivatives in (12), we get:

$$
\begin{aligned}
& \frac{\partial \Omega}{\partial g_{1}}=v^{\prime} \boldsymbol{g} g_{1} \boldsymbol{\Psi}+ \\
& +\left\{x-v \text { @ } g_{1} \boldsymbol{Q}^{\prime \prime}+2 x^{\prime} y^{\prime} \gamma^{\prime}-(1-\pi)\left[x^{\prime \prime} \mathbf{Q} \mathbf{g}_{+} x^{\prime} y^{\prime \prime}\right]\right\}_{d g_{1}}^{d s} \\
& \frac{\partial \Omega}{\partial \bar{\pi}}=x^{\prime} y^{\prime} \\
& \frac{d s}{d g_{1}}=w^{\prime} \mid g_{1}\left(-w^{\prime} \mid 1-g_{1}\right. \text { ! , }
\end{aligned}
$$

by definition of $s$ and the budget constraint. Inserting these individual derivatives into the total differential (12) and rearranging, we arrive at 


$$
\frac{d g_{1}}{d \bar{\pi}}=\frac{A}{B+C A}
$$

where

$$
\begin{aligned}
& A \equiv v^{\prime} \mid 1-g_{1} !+x^{\prime} y^{\prime}\left[w^{\prime} \mid g_{1}\left(-w^{\prime} \mid 1-g_{1} !\right.\right. \\
& B \equiv v^{\prime \prime} \mid g_{1}\left(+\pi v^{\prime \prime} \mid \mathbf{1}-g_{1} \mathbf{l}-\Omega\left[w^{\prime \prime} \mid g_{1}\left(+w^{\prime \prime} \mid \mathbf{l}-g_{1}\right]+\right.\right.
\end{aligned}
$$

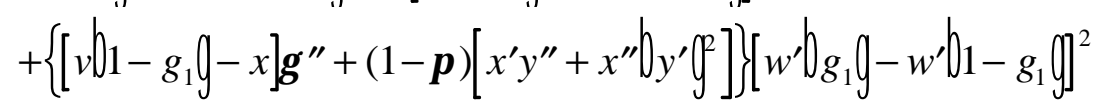

$$
\begin{aligned}
& C \equiv-2 \gamma^{\prime}\left[w^{\prime}\left|g_{1} !-w^{\prime}\right| 1-g_{1} !\right.
\end{aligned}
$$

Now note that $B+C A=-|\overline{\boldsymbol{H}}|$. Therefore, $B+C A<0$. Moreover, $A$ is simply the lefthand side of assumption (7), presented on p. 6; hence, $A \geq 0$. So,

$$
\frac{d g_{1}}{d \bar{\pi}} \leq 0
$$

which concludes the proof.

\section{References}

Alesina, Alberto and Rosenthal, Howard (1988), Partisan Cycles in Congressional Elections and the Macroeconomy, Working Paper No. 2706, September, Cambridge (U.S.A.): National Bureau of Economic Research.

(1995), Partisan Politics, Divided Government, and the Economy, New York: Cambridge University Press.

AlesinA, Alberto and RoubINI, Nouriel (1992), "Political Cycles in OECD Economies", The Review of Economic Studies, Vol. 59, No. 4, pp. 663-688.

AlesinA, Alberto, COHEN, Gerard D. and Roubini, Nouriel (1993), "Electoral Business Cycles in Industrial Democracies", European Journal of Political Economy, Vol. 9, No. 1, pp. 1-23.

BALEIRAS, Rui N. (1997), "Electoral Defeats and Local Political Expenditure Cycles", Economics Letters, Vol. 56, No. 2, pp. 201-207.

(1998), Local Finance in Portugal: Rules and Performance, Working Paper No. 320, January, Lisbon: Universidade Nova de Lisboa, Department of Economics. Available online at http://www.fe.unl.pt/FE/portugues/quemequem/servdoc/BAN/wp-2001.htm

BALEIRAS, Rui N. and SAntos, Vasco (2000), "Behavioral and Institutional Determinants of Political Business Cycles", Public Choice, Vol. 104, Nos. 1-2, pp. 121-147.

(2001), “On the Likelihood and Welfare Effects of 'Stop-and-go' Policies”, Journal of Public Economic Theory, forthcoming.

BALESTRA, Pietro (1992), "Introduction to Linear Models for Panel Data”, in László Mátyás and Patrick Sevestre (eds.), The Econometrics of Panel Data: Handbook of Theory and Applications, pp. 21-29, Dordrecht (The Netherlands): Kluwer Academic Publishers.

Blais, André and NADEAU, Richard (1992), “The Electoral Budget Cycle”, Public Choice, Vol. 74, No. 4, pp. 389403. 
Brennan, Geoffrey and BuChanAn, James M. (1980), The Power to Tax: Analytical Foundations of a Fiscal Constitution, New York: Cambridge University Press.

Costa, José da S. (1996), Performance of Local Governments in Portugal: a Tentative Evaluation, mimeo, paper presented at the $36^{\text {th }}$ European Congress of the Regional Science Association, August, Zurich: Swiss Federal Institute of Technology.

DRAZEN, Allen (2000), The Political Business Cycle After 25 Years, mimeo, May, Jerusalem: Hebrew University of Jerusalem. Available online at http://www.yale.edu/leitner/pdf/drazen.pdf.

Dur, Robert A., Peletier, Ben D. and Swank, Otto H. (1998), The Effect of Fiscal Rules on Public Investment if Budget Deficits are Politically Motivated, mimeo, paper presented at the 1997 European Public Choice Society Meetings, April, Prague: Prague University of Economics.

FISHER, Ronald C. (1996), State and Local Public Finance, second edition, Chicago: Irwin.

FreY, Bruno S. (1997), “Introduction”, in Bruno S. Frey (ed.), Political Business Cycles, pp. xi-xvii, Cheltenham (U.K.): Edward Elgar.

FREY, Bruno S. and SCHNEIDER, Friedrich (1978), "An Empirical Study of Politico-Economic Interaction in the United States", The Review of Economics and Statistics, Vol. 60, No. 2, pp. 174-183.

GREENE, William H. (1993), Econometric Analysis, second edition, New York: MacMillan Publishing Company.

HSIAO, Cheng (1986), Analysis of Panel Data, New York: Cambridge University Press.

(1992), "Random Coefficients Models", in László Mátyás and Patrick Sevestre (eds.), The Econometrics of Panel Data: Handbook of Theory and Applications, pp. 72-94, Dordrecht (The Netherlands): Kluwer Academic Publishers.

KEECH, William R. (1995), Economic Politics: the Costs of Democracy, New York: Cambridge University Press.

KrAAN, Dirk-Jan (1996), Budgetary Decisions: a Public Choice Approach, Cambridge (U.K.): Cambridge University Press.

LEVERNIER, William (1992), "The Effect of Relative Economic Performance on the Outcome of Gubernatorial Elections", Public Choice, Vol. 74, No. 2, pp. 181-190.

Lohmann, Susanne (1998), "Rationalising the Political Business Cycle: a Workhorse Model”, Economics \& Politics, Vol. 10, No. 1, pp. 1-17.

MAs-Colell, Andreu, Whinston, Michael D. and GREEN, Jerry R. (1995), Microeconomic Theory, New York: Oxford University Press.

MÁTYÁS, László (1992), "Error Components Models", in László Mátyás and Patrick Sevestre (eds.), The Econometrics of Panel Data: Handbook of Theory and Applications, pp. 46-71, Dordrecht (The Netherlands): Kluwer Academic Publishers.

MCNutT, Paddy A. (1996), The Economics of Public Choice, Cheltenham (U.K.): Edward Elgar.

MozzICAFreddo, Juan, GuERRA, Isabel, FERnANDES, Margarida A. and QuINTElA, João P. (1991), Gestão e Legitimidade no Sistema Politico Local [Management and Legitimacy in the Local Political System], Lisbon: Escher.

NordHAUS, William D. (1989), “Alternative Approaches to the Political Business Cycle”, in William C. Brainard and George L. Perry (eds.), Brookings Papers on Economic Activity, Vol. 2, pp. 1-49.

PEREIRA, Paulo T. (1996), “A Politico-Economic Approach to Intergovernmental Lump-Sum Grants”, Public Choice, Vol. 88, Nos. 1-2, pp. 185-201.

PERSSON, Torsten, RolAnd, Gérard and TABELlinI, Guido (1998), Towards Micropolitical Foundations of Public Finance", European Economic Review, Vol. 42, Nos. 3-5, pp. 685-694.

PERSSON, Torsten and TABEllini, Guido (1990), Macroeconomic Policy, Credibility and Politics, Chur (Switzerland): Harwood Academic Publishers.

REED, W. Robert (1994), “A Retrospective Voting Model with Heterogeneous Politicians”, Economics \& Politics, Vol. 6, No. 1, pp. 39-58.

RogofF, Kenneth (1990), "Equilibrium Political Budget Cycles", The American Economic Review, Vol. 80, No. 1, pp. 21-36.

ROUBINI, Nouriel and SACHS, Jeffrey D. (1989a), "Government Spending and Budget Deficits in the Industrial Countries”, Economic Policy, Vol. 8, April, pp. 99-132. 
(1989b), "Political and Economic Determinants of Budget Deficits in the Industrial Democracies", European Economic Review, Vol. 33, No. 5, pp. 903-938.

SCHuKneCht, Ludger (1999), Fiscal Policy Cycles and the Exchange Rate Regime in Developing Countries, European Journal of Political Economy, Vol. 15, Issue 3, pp. 569-580.

(2000), "Fiscal Policy Cycles and Public Expenditure in Developing Countries", Public Choice, Vol. 102, Nos. 1-2, pp. 115-130.

SHACHAR, Ron (1993), "Forgetfulness and the Political Cycle", Economics \& Politics, Vol. 5, No. 1, pp. 15-25.

Soldatos, Gerasimos T. (1994), "The Electoral Cycle: a Brief Survey of Literature", Revue d'Économie Politique, Year 104, No. 4, pp. 571-587.

SuZUKI, Motoshi (1994), "Evolutionary Voter Sophistication and Political Business Cycles", Public Choice, Vol. 81, Nos. 3-4, pp. 241-261.

TABEllini, Guido and AlesinA, Alberto (1990), "Voting on the Budget Deficit", The American Economic Review, Vol. 80, No. 1, pp. 37-49. 